\title{
Raising the Achievement of Caribbean Pupils in British Schools: unacknowledged problems and challenges for policy makers
}

\author{
FEYISA DEMIE \\ Research and Statistics Unit, Lambeth Education, UK [1]
}

\begin{abstract}
Over the last decade the underperforming groups issues that have shaped thinking practice in schools have changed significantly. Today, a high level of education is no longer a luxury for some groups or social classes, but a necessity for every one in British society. Yet Black Caribbean heritage pupils' achievements lag far behind the average achievement of the majority of their peers and the gap is growing at the end of primary and secondary education. Despite much academic debate and policy makers' concern about underachievement in schools, the needs of Black Caribbean pupils have not been addressed in the education system and have been largely neglected. This research paper examines critically the national policy agenda, the extent of and reasons for underachievement of pupils of Black Caribbean heritage throughout each key stage in an inner city LEA. Statistical trends and patterns of performance are analysed by ethnic factors to illustrate differences in attainment. The paper questions the current national policy agenda for improving achievement for all pupils, and argues critically that the issues surrounding Black Caribbean pupils' underachievement are real and should not be underestimated in national policy formulation. Policy implications for government and for all concerned with school improvement are highlighted, as well as many practical suggestions.
\end{abstract}

\section{Introduction}

The last decade of the twentieth century saw much debate amongst schools, academic researchers, and policy makers about the achievement of Caribbean pupils in British schools. There is no doubt that Caribbean pupils' underachievement is currently also a 'hot issue' within education. This concern has been fuelled recently by media attention through headlines such as 'Teachers are failing Black boys' (Observer, January 6, 2002), 'Fasttracking will penalise Black pupils' (BBC News, 12 March, 2002), 'Schools told to do more for Black pupils' (BBC News, 9 December, 1998), 'Task Force to help Black pupils' (BBC News, 16 March, 2002), 'Schools called to account for ethnic divide' (Guardian, 7 May, 2002).

What is more, most of the studies in the field of school improvement in the past decade show that the notion of Caribbean pupils' underachievement in British schools is in danger of becoming accepted as an irrefutable fact. For instance, the most extensive review of 
research relating to Caribbean heritage children in British schools between 1965 to 1980 suggested that 'there is an overwhelming consensus that research evidence shows a strong trend to underachievement of pupils (our emphasis) of West Indian origin' (Taylor, 1981, p. 216; Tomlinson 1983).

The relative underachievement of ethnic minority pupils has also been a major issue in national education policy formulation. An inquiry committee reported on the issue twice during the 1980s. The first official recognition of the problem was The Rampton Report (Rampton, 1981), which was the interim report of the Committee of Inquiry into Education of Children of Ethnic Minority Groups. This report dealt in detail specifically with the underachievement of pupils of Caribbean backgrounds and concluded, 'West Indian Children as a group are underachieving in our Education System’ (Rampton, 1981, p. 80). The Swann Report (Swann, 1985) also gives a good deal of attention of the underachievement of pupils of Caribbean backgrounds, and confirms the finding of the Rampton report. Thus the Swann report concludes 'there is no doubt that the West Indian children, as a group, and on average, are underachieving, both by comparison with their school fellows in the White majority, as well as in terms of their potential. Notwithstanding that some are doing well' (Swann, 1985, p. 81).

The Inner London Education Authorities have also monitored educational achievement by ethnic background as part of their equal opportunities policies. This practice was started by ILEA and continued by all inner London LEAs that emerged since 1990. For example, empirical studies by ILEA in London, disaggregating the ethnic groups, show a disturbing pattern of low attainment of Black Caribbean and Bangladeshi heritage pupils compared to African, English/Scottish/Welsh/Irish, Indian and Pakistani (see ILEA, 1987; Nuttall, 1990). Recent studies coordinated by the Association of Metropolitan Authorities (AMA) and National Foundation for Educational Research (NFER) for 9 LEAs in inner London consisting of 116 secondary schools between 1993 and 1998 also showed similar patterns (Thomas et al., 1994; Kendall, 1998; Demie, 2001). These studies are more sophisticated in terms of the methodology (multilevel modelling) and complexity of the data and were carried out continuously for six years with the help of London LEAs' research and statistics officers. The statistical technique used looked at data, both the pupil and school level and controls for factors such as gender, verbal reading band, ethnicity, free school meals, management (church/state) and school status (comprehensive, selective and independent). These investigations and analysis were repeated every year between 1993 and 1998 and the findings suggest that Black Caribbean pupils are significantly underachieving in inner London LEAs compared to their peers. In conclusion the researchers argued while the findings presented in these studies can not be regarded as conclusive because of the limitation with the data, they can, however be sure that the Black Caribbean underachievement as a whole is real, and overall they receive relatively poor GCSE results at the end of their secondary education compared to their peers in schools. The findings of the study also suggested that the other main ethnic minority groups' performance may now exceed that of the majority group English/Scottish/Welsh (see Thomas et al., 1994; Kendall, 1998). The underperformance of White compared to main ethnic groups such Indian and Chinese is not surprising as the English/Scottish/Welsh population of inner London is not representative socially or economically of the total population of the UK (Nuttall et al., 1989; Demie, 2001).

Research in the 1980s and 1990s reflected the earlier findings, with Caribbean pupils continuing to make less progress on average than other pupils (Mabey, 1981; Mortimore et al., 1988; Nuttall et al., 1989; Kendall, 1998; Gillborn \& Gipps, 1996; Demie, 2001). Each of these studies appeared to show considerable underachievement of Caribbean pupils in comparison with the achievement of White and Asian pupils. These research findings have 


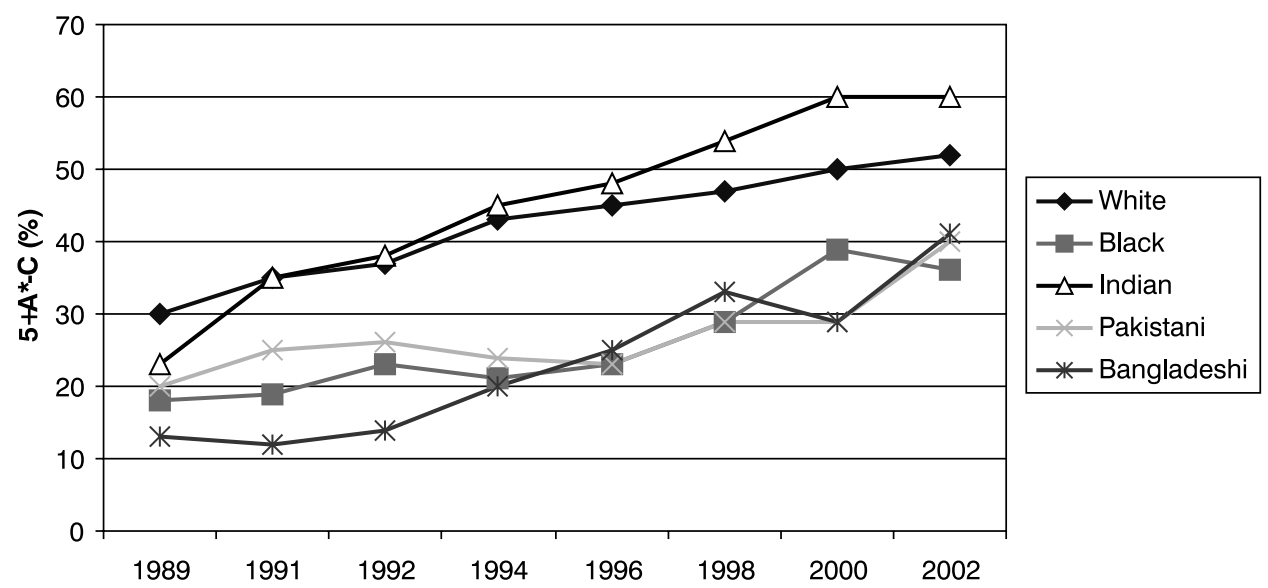

Figure 1. Changes in GCSE attainment by ethnicity in England and Wales, 1989-2002 (5+ A*-C) Source: Youth Cohorts Study, Department for Education and Skills (2002) and Demack et al. (2000).

profound implications on the credibility of the education system for addressing the underachievement of underperforming groups and perhaps most importantly for the relationship of the Caribbean communities to the current education system.

The previous OFSTED review of research in this area also described the differences in attainment between certain ethnic groups (Gillborn \& Gipps, 1996; Gillborn \& Mirza, 2000). This review noted that the gap is growing between the highest and lowest achieving ethnic groups in many LEAs, and that African and Caribbean pupils, especially boys, have not shared equally in the increasing rates of educational achievement. The review concluded that 'black pupils generally may be falling further behind the average achievement of the majority of their peers' (Gillborn \& Gipps, 1996, p. 29). The authors warned, however, that the quality of data available nationally was not of a high standard and the ethnic categories were relatively crude.

Recent OFSTED reports further state that:

The evidence that has been available from individual LEAs has tended to show that the relative performance of Black Caribbean pupils begins high, starts to decline in Key Stage 2, tails off badly in Key Stage 3 and is below that of most other ethnic groups at Key Stage 4. (OFSTED, 2002, p. 1)

The above findings are also supported by the national Youth Cohort Study (YCS) of England and Wales, which provides some of the useful data on education and ethnicity. Figure 2 shows a clear picture of how different ethnic groups shared unequally in the changing rates of attainment during the late 1990s. A striking finding is that members of each main ethnic group are now more likely to attain higher grades than ever before. The data in Figure 1 also reveals that there are considerable differences in attainment of different ethnic groups. During the period between 1989 and 2002, Indian pupils' performance improved from $23 \%$ to $60 \%$ (an increase of 37 percentage points), followed by White, who moved from $30 \%$ to $52 \%$ ( +22 points), Black pupils moved from $18 \%$ to $36 \%$ ( +18 points), Bangladeshi from $13 \%$ to $41 \%$ ( +28 points) and Pakistani from $20 \%$ to $40 \%(+20$ points). Only the White and Indian groups enjoyed a year-on-year improvement. The Black pupils are markedly less likely to attain five higher GCSEs than their White, Indian, 
Bangladeshi and Pakistani peers nationally and its performance declined by $3 \%$ between 2000 and 2002. The improvement in the attainment of Black pupils was not enough to keep pace with their White peers. The main conclusion from the YCS data is that Black pupils have drawn little benefit from the rising levels of attainment and the gap between them and their White peers is as wide now as a decade ago.

However, the YCS data are not without limitations and care needs to be taken in the interpretation of the data. There has been a tendency to homogenise ethnic minority groups in the survey. For example, the issue of African and Caribbean underachievement has been complicated by the problems of categorising different ethnic groups within the broadly defined African-Caribbean group in the YCS survey. The use of the term may obscure significant difference and achievement between pupils with family origins in the Caribbean and those of an African ethnic background. No national statistics are available at present that are better than the YCS survey, but research from an LEA in England with a very high proportion of Black African and Caribbean pupils suggests that the pupils with a Black African background tend to achieve relatively higher results at GCSE than their Black Caribbean peers (see Demie, 2001). The situation is too complex for the simple conclusion of African-Caribbean underachievement or Black underachievement. Overall, the findings from YCS aggregate statistics are unhelpful for drawing conclusions about the underachievement of Caribbean pupils at a national level and for formulating policies.

In the absence of performance data and clear strategies at national level, it is easy to turn a blind eye to underperforming groups of pupils and for scarce resources to be dissipated on the wrong priorities. Overall the impact of government polices on raising the achievement of ethnic minorities in the last decade has been very limited, and indeed the gap between White pupils and Black pupils may be widening. A recent research finding confirms that educational inequalities have increased and that African, Caribbean and Pakistani pupils particularly have not shared equally the rising levels of GCSE attainment (Gillborn \& Mirza, 2000).

It is within this context that the current research is undertaken. The main aim is to examine how different groups share in the rising levels of attainment at the end of primary and secondary schooling. This research paper also critically examines the national policy agenda, the extent of, and reasons for the underachievement of pupils of Caribbean heritage throughout primary and secondary schools in an inner city LEA. Statistical trends and patterns of performance have been analysed by gender and ethnic factors to illustrate differences in attainment.

\section{The Concept of Underachievement}

There has been widespread misunderstanding of the concept of the term 'underachievement'. In recent years the term was used to describe the difference in the average educational attainment of different groups. It has become common to see underachievement as a phenomenon relating to particular groups of learners who experience disadvantages that call for additional support. These are identifiable groups whose levels of attainment tend to be lower than those of other groups for no obvious reasons other than their group characteristics and the inadequacy of the education system in responding to those characteristics. The groups that require attention in this way include ethnic minority groups, boys, mobile children, EAL children and looked after children. However, the usefulness of the term 'underachievement' has recently been questioned, the argument being that the notion of underachievement has become a stereotype and even sometimes wrongly related 
to an outdated older concept of ability that 'each individual had a more or less fixed potential and there is little that can be done to increase a learner's potential' (DETR, 2001, p. 1). The assumption on which this view is based has long been attacked (see Gillborn, 2002; Kamin, 1977). Underachievement is nothing to do with fixed potential or ability: it is the consequence of ineffective educational practices, which prevent the potential of learners being realised (Gillborn, 2002).

The current government has now adopted this concept of underachievement, and it views it as the product of inadequacy of the education system rather than of poverty or other social factors alone.

We must have high expectations of everyone, regardless of background, gender or circumstances. We must target support to those who need most help to reach those high standards and we must change the culture. (Blunkett, 2000, p. 4)

We think the notion of underachievement should emphasise the difference in attainment between groups and is a useful concept particularly to identify an inequality of opportunities. Therefore, in this paper 'underachievement' is used, stressing the sense of being 'under', as the Caribbean pupils are the lowest achievers of the main ethnic groups.

\section{Methods}

Background to the Case Study LEA

This research paper considers evidence from an inner London Authority. The LEA is one of the most ethnically, linguistically and culturally diverse boroughs in Britain. About $73 \%$ of pupils are from Black and ethnic minority groups. The 2001 census shows that there were 28,384 pupils in the LEA's schools. Of these, English/Scottish/Welsh pupils formed the largest ethnic group with $23.6 \%$, followed by Caribbean at $22.8 \%$, African at $22.1 \%$, Other Black 11\%, Other White $7.2 \%$ and Portuguese $4.6 \%$.

There has been a change in the overall composition of the Black and ethnic minority population in the LEA. The 1991 census showed that overall $66 \%$ of pupils in the LEA's schools belonged to Black and other ethnic minority communities, compared to $73 \%$ in 2001.

Of all English LEAs, the borough serves the largest proportion of Caribbean pupils and any findings from our study therefore have significant importance for formulating policies and strategies aimed at raising the achievement of Caribbean pupils at both national and local level.

\section{The Dataset}

The sample consisted of pupils who completed National Curriculum Assessment tests at the end of KS1, KS2, KS3 and KS4. The data were collected across four cohorts who completed their key stage tests in 1998, 1999, 2000 and 2001 respectively in an inner London LEA. In addition all the LEA's schools were asked to provide details of their pupils' backgrounds such as name, date of birth, sex, ethnic background, free school meals, date of admission or mobility data and levels of fluency in English for contextual analysis. Where available we also drew evidence from national data published by the Department of Education and Skills (DfES). 


\section{F. Demie}

\section{Measures of Performance}

It is important to note that in the English education system, pupils aged 5 to 16 years are taught the National Curriculum subjects and are tested in English, mathematics and science. These tests are age-dependent and divided into four key stages: KS1, KS2, KS3 and KS4. They are intended to show whether children have reached the National Curriculum learning targets standard, which range from 1 to 8 between Key Stage One (KS1) and Key Stage Three (KS3). Pupils climb the levels as they get older and learn more. Thus, a typical seven-year-old is expected to achieve level 2B, an eleven-year-old level 4 and fourteen-year-old level 5 . At the end of KS4, most 15- and 16-year-olds also take General Certificate of Secondary Education (GCSE) exams. These are the major qualifications taken by pupils at the end of compulsory schooling at the age of 15 , and are a series of examinations in the individual subjects the pupils have been studying. Therefore the measure of performance used in the analysis is level 2B or above for KS1 performance, level 4 or above for performance at KS2, level 5 or above for KS3 and $5+A^{*}$-C for GCSE. An overall indicator of pupil attainment in KS1, KS2 and KS3 was also derived by taking of the average of the three tests-English, mathematics and science for each school and the LEA.

\section{Terminology and the People of Caribbean Heritage}

The terminology used to refer to people of Caribbean heritage has been problematic in Britain. There has been misuse and abuse of the term and a number of authors use the words West Indian, African Caribbean, Afro-Caribbean and Black, Caribbean or Black Caribbean, African or Black interchangeably (see McKenley et al., 2003; Demie, 2001; Gillborn \& Gipps, 1996; Gillian \& Richardson, 2003; Sewell, 1995; Blair et al., 1998). In some cases it has been used in the context of political and historical developments ignoring educational debates. This has confused and complicated underachievement issues of pupils of Caribbean origins. In this paper, we will argue that it is important to be clear on the concept of African and Caribbean origins and differentiate between pupils from Africa and pupils who were born in the Caribbean or whose parent/s have Caribbean origins.

In education, the term 'West Indian' was first used in the Rampton report (Rampton, 1981) to refer to pupils of Caribbean origins and was changed to 'Afro-Caribbean' as this was preferable to West Indians in the 1980s. This was followed by 'African Caribbean', which started appearing in the early 1990s as a direct analogy with the US terminology 'African-American' that was adopted after the civil rights movement in America. The situation is further complicated by the range of these terms in different academic papers (see Blair et al., 1998; Sewell, 1997), which use some of these confusing terminologies without questioning the implications. Gillborn and Gipps (1996) were the first to raise questions about the problems with terminology and the lack of differentiation between African and Caribbean in national data collection. Because of these problems with categorisation, they used the terms 'African Caribbean' and 'Black' in their research. In their report, 'Black' included 'individuals who would appear in census statistics as either Black Caribbean, Black African and Other Black' (p. 8). They used 'African Caribbean' to mean African and Caribbean, depending on how the data is collected in different authorities. However, where data were available, this was further differentiated into 'African' and 'Caribbean' (see Gillborn \& Gipps, 1996), to clarify a focus on the underachievement of the two major Black ethnic groups in the UK. Gillborn and Gipps also argued that some use the terms 'African Caribbean' or 'Afro-Caribbean' for political purposes to 'symbolise a shared ethnic heritage and/or position within the British social-economic structure' (Gillborn \& Gipps 1996, p. 27). This view is supported by Gillian and Richardson (2003, p. 5), who pointed out that the term was "considered by Black people of Caribbean heritage to be a clearer affirmation 
of their identity than the current Afro-Caribbean' which was adopted as being preferable to the 'West Indian' term used in the Rampton report.

However, use of the term 'African Caribbean' has obscured a significant difference in the achievement of pupils with family origins in the Caribbean, those of African ethnic backgrounds, and pupils who consider themselves to be Black British. A previous national DfES national Youth Cohort Survey (YCS) as argued above has attempted to homogenise ethnic minorities by using the term 'Black' to refer to all African and Caribbean pupils. This problem is even further complicated by the recent DfES consultation paper 'Aiming High: raising the achievement of ethnic minority pupils', which uses the term 'African Caribbean' as a short hand phrase for 'all Black people of African, Caribbean, mixed heritage and those categorised as Black other' (DfES, May 2003, p. 32). This consultation paper ignores the current census good practice that recognises the heterogeneity of different groups both in ethnic backgrounds and educational experience. The DfES clearly takes a position that to focus on the concerns of Black Caribbean pupils is too narrow to be allowed. It does not help to improve our understanding of underachievement issues and the need to address issues facing different groups of pupils including Caribbean, African and Black British. Unfortunately, as noted by Gillian and Richardson (2003):

the term African Caribbean has been grossly misunderstood and misused by many civil servants, Officers in Local Government, EMAG teachers, academic researchers and has blurred the underachievement debate in Britain. It has been used interchangeably with the term Black. Others have used it to mean African and Caribbean.... Some have even spelt it as African/Caribbean, implying that the two words are close in meaning with the term Black as to be interchangeable.... It is unhelpful of the DfES to state that the discourse of educational policy should ignore the substantial differences between the cultures and circumstances of Caribbean people and those of people from the continent of Africa. The DfES paper is not only raising semantic issues by using incorrect terminology; the DfES encourages schools, local government to ignore the distinctive needs of Caribbean and African or Black British. (Gillian \& Richardson, 2003, p. 5, emphasis ours)

It is now widely recognised that there is a serious semantic problem in the categorisation of pupils of Caribbean or African origin. Among educationalists, there is little understanding about the meaning of the terminology and the issues involved and the difference between 'Black Caribbean' and 'African Caribbean'. There is therefore no general agreement among academics involved in this kind of work that one of the categories used is correct to reflect the people of Caribbean heritage, although most agree that Caribbean is a useful concept in the context of addressing the educational needs of pupils of Caribbean origins. The use of the term 'African Caribbean' is being increasingly challenged; not to question the distinctive needs, experience, and circumstances of Black Caribbeans, but because it has been used to blur or obscure underachievement issues at national and local levels.

The first serious attempt to look at the problem of categorisation was in the 1991 census, in which 'Black' was differentiated into 'African', 'Caribbean' and 'other'. This was further improved, after national debate, for the 2001 census to 'Black African', 'Black Caribbean' and 'Black Other'. As noted by McKenley et al. (2003, p. 7) 'Education takes its lead from that national debate and reflects the latest ethnic categories in the Pupil Level Annual Schools' Census (PLASC), but this is always a matter of contention'. The 2003 PLASC asked respondents to classify themselves in ethnic terms for the first time. The decision to ask questions about ethnicity followed a fierce debate, lengthy consultation and rigorous testing of potential questions. 
For the purposes of the research in the Authority, we favoured the term 'Caribbean' to define the children of birth families where at least one parent is of Caribbean heritage. This terminology has been used in Lambeth and in inner London since the 1990s. We need to recognise that not all Caribbean people are of African origin. Caribbean culture is the product of a unique historical experience and has been affected by numerous cross-cultural influences, including African, Indians, British, Dutch, French, Portuguese and Chinese. British born pupils of Caribbean origins also share this culture through their family background and country of origins' (see Gillian \& Richardson, 2003, p. 5). As noted by Ashrif (2002, p. 27) at 'least 48\% have their origins in the Indian subcontinent'. This figure may need further research but it clearly questions the use of African Caribbean terminology to refer to people of Caribbean origin in Britain.

Maintaining the focus of studies of underachievement will require that the terms 'African' and 'Caribbean' be used, as collected in PLASC. We argued in our previous research that:

Black Caribbean, used in PLASC data collection should be seen as an inclusive term, which would encompass those pupils of dual heritage, with one parent of Caribbean heritage. We take the view that issues of country of birth as opposed to origin, faith, location, and settlement all contribute to the concept of 'ethnicity', 'heritage' and 'background'. These are interwoven with a personal sense of affinity and belonging. Identities and how these might be reflected 'officially' are a lively debate every decade as the national census seeks to catch up with changes in categorisation over the previous decade. (McKenley et al., 2003, p. 7)

The term 'Black Caribbean' in PLASC makes sense for educational purposes, to statisticians and to the Caribbean and African community, as it clearly differentiates pupils of Caribbean origin from Black Africans, which in the past were often lumped together as African Caribbean or Afro-Caribbean on political grounds. It focuses clearly to address underachievement issues in educational debates and ensures that this focus is not lost or blurred in national policy formulation by providing unambiguous data for policy makers and schools. For this reason, in this study, we used the term 'Caribbean' to refer to pupils of Caribbean origin and 'African' to refer to pupils in African origin in Britain.

\section{Underachievement of Caribbean Pupils in British Schools: empirical evidence}

This section considers underachievement of Caribbean pupils at the LEA and national levels. The 1990s saw an improvement in the proportion of pupils attaining five or more higher grade passes in GCSE examinations at the end of secondary education in both the LEA and nationally. Figure 2 illustrates that there was a dramatic improvement in the achievement of pupils completing their compulsory schooling between 1989 and 2001. These figures show that the proportion of 15 -years-olds attaining at least five higher grade passes rose from $33 \%$ in 1989 to $50 \%$ in 2001 in England. This represents an improvement rate of 15\%. The LEA figure improved during the same period by $19 \%$.

It is difficult to ascribe the above pattern of improvement to education reform alone but the data from the LEA confirms how significant the government policy measures are in raising standards. However, not all ethnic groups shared equally in the overall improvement in attainment at the $5+\mathrm{A}^{*}$ - $\mathrm{C}$ level. As we will argue in the next section the government policy measures have also had a negative impact by increasing inequalities between different ethnic groups within the LEA and the education system. 


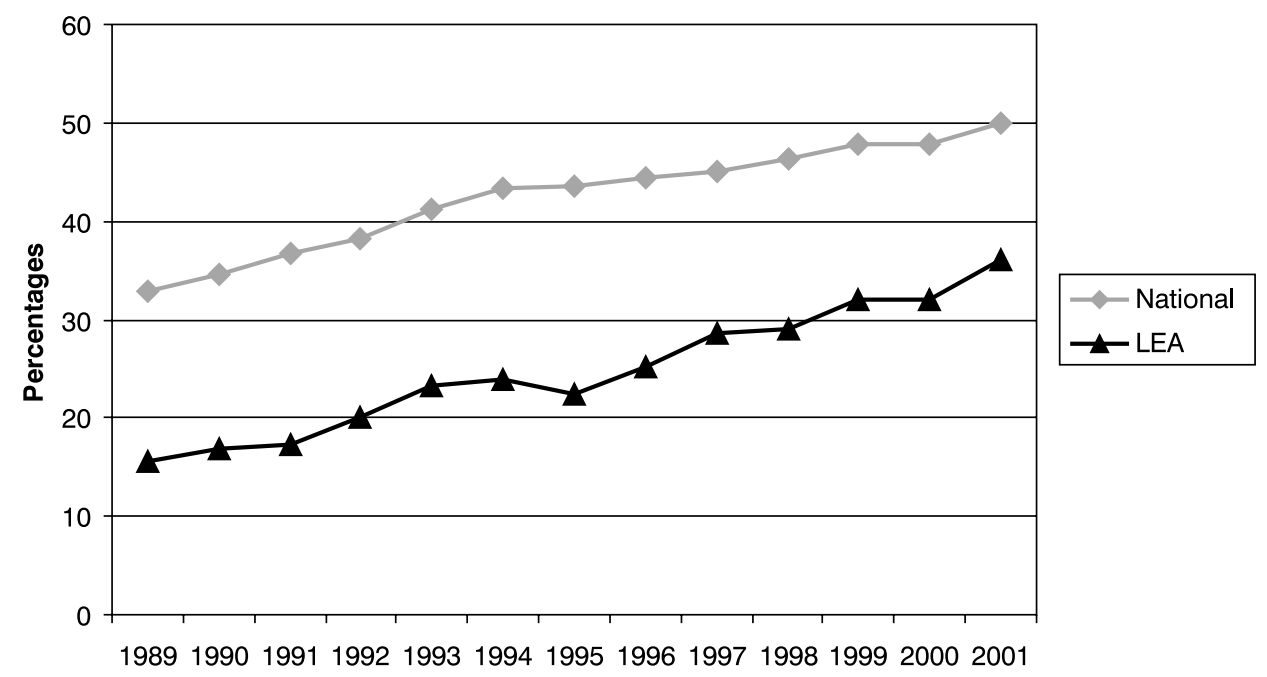

Figure 2. Proportion of pupils gaining $5+\mathrm{A}^{*}-\mathrm{C}$ passes 1989-2001

\section{Underachievement of Black Caribbean Pupils in Lambeth Schools}

KS2 and GCSE Evidence

This section looks in brief at the context of the LEA in terms of achievement of the main ethnic groups. The Authority has carried out considerable research in the achievement of all ethnic minorities group in the LEA schools (for details see Demie, 2001, 2002). The main finding of the previous studies suggest that:

Children from different ethnic groups show difference in educational attainment at the end of each key stage in the LEA. Indian, Vietnamese, Bangladeshi and Chinese have higher results, on average, than African, Caribbean, Irish and English/Scottish/Welsh pupils. Caribbean and Portuguese are the main underachieving groups. (Demie, 2001, p. 101)

The findings of the study also confirm the main ethnic groups are African, Caribbean and English/Scottish/Welsh. Indian, Vietnamese, Chinese, Bangladeshi and Chinese pupils are relatively small ethnic groups in the LEA, and so more difficult to draw firm conclusions from the data. (Demie, 2001, p. 98)

Table 1 Changes in attainment by ethnic origin in LEA schools

\begin{tabular}{|c|c|c|c|c|c|c|c|c|c|c|c|}
\hline & \multicolumn{6}{|c|}{ KS2 average results - level $4+(\%)$} & \multicolumn{5}{|c|}{$\operatorname{GCSE}\left(\% 5+A^{*-C}\right)$} \\
\hline & 1998 & 1999 & 2000 & 2001 & 2002 & $\begin{array}{l}\text { Change } \\
98-02\end{array}$ & 1999 & 2000 & 2001 & 2002 & $\begin{array}{l}\text { Change } \\
99-02\end{array}$ \\
\hline African & 59 & 69 & 73 & 74 & 74 & 15 & 35 & 38 & 44 & 40 & 6 \\
\hline Caribbean & 49 & 57 & 67 & 68 & 67 & 18 & 24 & 20 & 23 & 30 & 6 \\
\hline ESW & 60 & 70 & 74 & 78 & 77 & 17 & 34 & 32 & 32 & 36 & 2 \\
\hline LEA & 55 & 65 & 71 & 73 & 72 & 17 & 32 & 32 & 36 & 41 & 9 \\
\hline
\end{tabular}




\section{F. Demie}

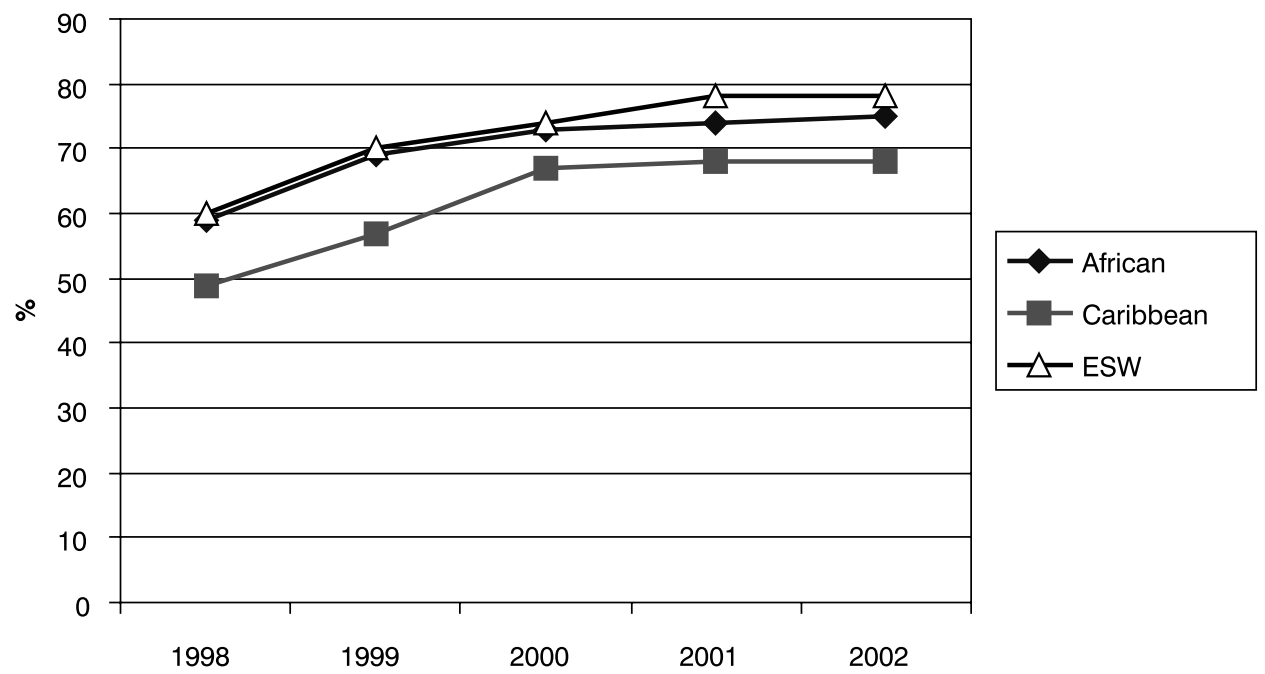

Figure 3. Gaps in KS2 performance between main ethnic groups in the LEA (\% Level $4+$ )

Here we briefly consider recent findings on the main ethnic groups in the LEA focusing on Black Caribbean achievement compared to African and English/Scottish and Welsh achievement.

The findings from Table 1 and Figure 3 indicate that the KS2 results have shown a steady increase over the last four years. However, when the main ethnic groups are considered, it can be seen that not all groups have enjoyed these gains equally. Of the main ethnic groups, African pupils made the least improvement over the four years.

An analysis of GCSE results by ethnic background also reveals a contrasting picture of performance between different ethnic groups and suggests that pupils of different ethnic heritage do not experience equal educational opportunities (see Table 1 and Figure 4).

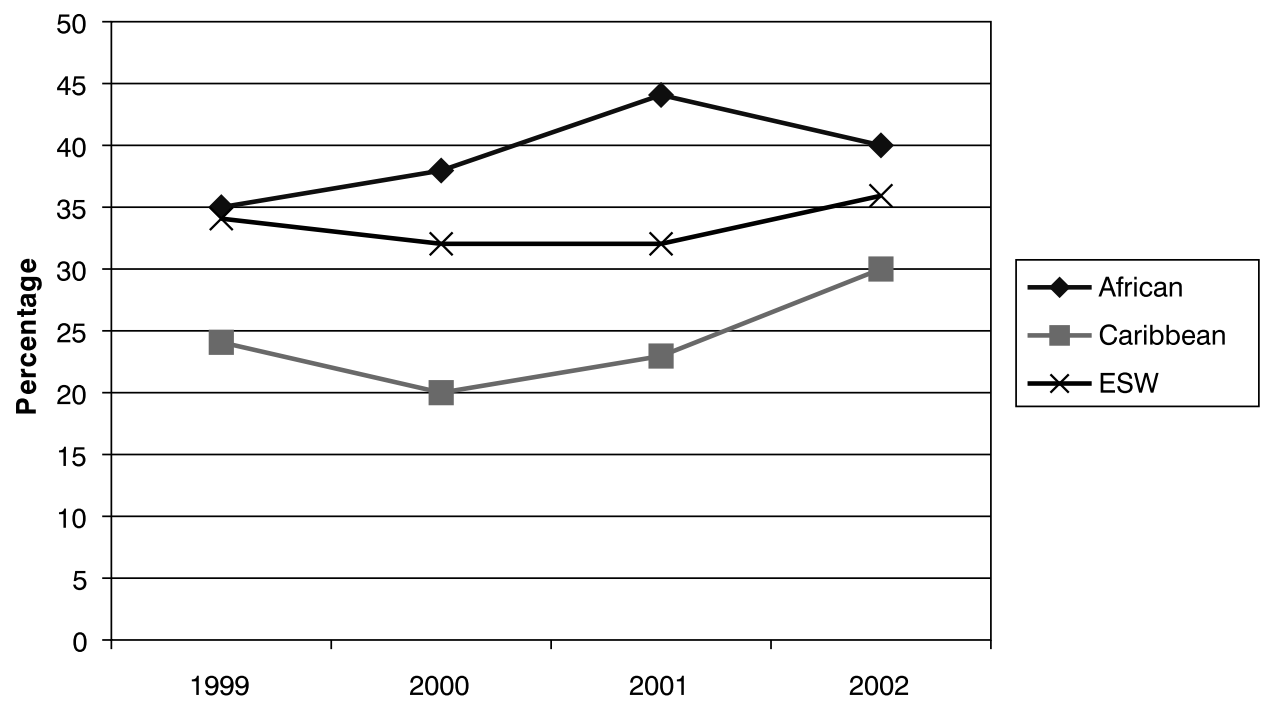

Figure 4. Performance gaps of main ethnic groups at GCSE $(\% 5+\mathrm{A} *-\mathrm{C})$ 
Table 2 Performance by key stage, gender and ethnic background (percentage)

\begin{tabular}{|c|c|c|c|c|c|c|c|c|c|}
\hline \multirow[t]{2}{*}{ Ethnic groups } & \multirow[t]{2}{*}{ Year } & \multicolumn{4}{|c|}{ KS2 (level $4+$ ) } & \multicolumn{4}{|c|}{$\operatorname{GCSE}\left(5+A^{*-C}\right)$} \\
\hline & & All & Boys & Girls & Diff. & All & Boys & Girls & Diff. \\
\hline \multirow[t]{5}{*}{ African } & 1998 & $60 \%$ & $56 \%$ & $62 \%$ & $6 \%$ & $\mathrm{n} / \mathrm{a}$ & $\mathrm{n} / \mathrm{a}$ & $\mathrm{n} / \mathrm{a}$ & $\mathrm{n} / \mathrm{a}$ \\
\hline & 1999 & $69 \%$ & $66 \%$ & $73 \%$ & $7 \%$ & $35 \%$ & $33 \%$ & $37 \%$ & $4 \%$ \\
\hline & 2000 & $73 \%$ & $71 \%$ & $75 \%$ & $4 \%$ & $38 \%$ & $32 \%$ & $41 \%$ & $9 \%$ \\
\hline & 2001 & $72 \%$ & $72 \%$ & $75 \%$ & $2 \%$ & $44 \%$ & $32 \%$ & $52 \%$ & $20 \%$ \\
\hline & 2002 & $74 \%$ & $72 \%$ & $76 \%$ & $4 \%$ & $42 \%$ & $35 \%$ & $45 \%$ & $10 \%$ \\
\hline \multirow[t]{5}{*}{ Caribbean } & 1998 & $49 \%$ & $43 \%$ & $55 \%$ & $11 \%$ & $\mathrm{n} / \mathrm{a}$ & $\mathrm{n} / \mathrm{a}$ & $\mathrm{n} / \mathrm{a}$ & $\mathrm{n} / \mathrm{a}$ \\
\hline & 1999 & $56 \%$ & $54 \%$ & $61 \%$ & $6 \%$ & $24 \%$ & $15 \%$ & $28 \%$ & $13 \%$ \\
\hline & 2000 & $66 \%$ & $63 \%$ & $70 \%$ & $7 \%$ & $20 \%$ & $14 \%$ & $23 \%$ & $9 \%$ \\
\hline & 2001 & $67 \%$ & $63 \%$ & $73 \%$ & $11 \%$ & $23 \%$ & $18 \%$ & $25 \%$ & $7 \%$ \\
\hline & 2002 & $67 \%$ & $66 \%$ & $68 \%$ & $2 \%$ & $33 \%$ & $26 \%$ & $36 \%$ & $10 \%$ \\
\hline \multirow[t]{5}{*}{ ESW } & 1998 & $61 \%$ & $57 \%$ & $64 \%$ & $6 \%$ & $\mathrm{n} / \mathrm{a}$ & $\mathrm{n} / \mathrm{a}$ & $\mathrm{n} / \mathrm{a}$ & $\mathrm{n} / \mathrm{a}$ \\
\hline & 1999 & $69 \%$ & $67 \%$ & $72 \%$ & $4 \%$ & $34 \%$ & $34 \%$ & $35 \%$ & $1 \%$ \\
\hline & 2000 & $72 \%$ & $72 \%$ & $76 \%$ & $4 \%$ & $32 \%$ & $32 \%$ & $32 \%$ & $0 \%$ \\
\hline & 2001 & $77 \%$ & $76 \%$ & $80 \%$ & $5 \%$ & $32 \%$ & $33 \%$ & $31 \%$ & $-2 \%$ \\
\hline & 2002 & $77 \%$ & $75 \%$ & $80 \%$ & $5 \%$ & $36 \%$ & $36 \%$ & $37 \%$ & $1 \%$ \\
\hline \multirow[t]{5}{*}{ LEA } & 1998 & $55 \%$ & $50 \%$ & $57 \%$ & $7 \%$ & $29 \%$ & $25 \%$ & $32 \%$ & $7 \%$ \\
\hline & 1999 & $65 \%$ & $63 \%$ & $67 \%$ & $4 \%$ & $32 \%$ & $27 \%$ & $35 \%$ & $8 \%$ \\
\hline & 2000 & $71 \%$ & $68 \%$ & $73 \%$ & $5 \%$ & $32 \%$ & $28 \%$ & $35 \%$ & $7 \%$ \\
\hline & 2001 & $73 \%$ & $70 \%$ & $75 \%$ & $5 \%$ & $36 \%$ & $29 \%$ & $38 \%$ & $9 \%$ \\
\hline & 2002 & $72 \%$ & $70 \%$ & $72 \%$ & $2 \%$ & $40 \%$ & $33 \%$ & $42 \%$ & $9 \%$ \\
\hline
\end{tabular}

The African pupils made good improvement between 1999 and 2001 but then fell back in 2002, but overall they still are the highest achieving of the main ethnic groups. Caribbean pupils were consistently the lowest performing group.

Gender and Black Caribbean Achievement

Table 2 repeats the pattern established earlier, whereby girls tend to outperform boys at each key stage (see Demie, 2001; Gillborn \& Gipps, 1996). Overall, the findings of the results between key stages indicate that girls achieve higher averages than boys by a quite noticeable margin. This is true for African, Caribbean and ESW pupils at all key stages. It also confirms that for Caribbean pupils, the gap in performance between boys and girls is higher than for African and ESW pupils, suggesting the underachievement of boys. Overall, this finding questions some of the previous studies which argued that only Black boys, and not girls, face inequalities. The data in Table 2 confirm that both Black Caribbean girls and boys were lagging behind White boys and all three groups were some distance behind White girls.

Social Economic Disadvantage and Underachievement of Black Caribbean Pupils

The free school meals variable is often used as a proxy measure of the extent of social deprivation in the backgrounds of pupils and has been linked to underachievement in a number of studies (see Gillborn \& Youdell, 2002; Demie, 2001). The proportion of pupils taking KS2 in 2002 who were eligible for free school meals (FSM) was 41\%, and for the GCSE cohort, it was $43 \%$. Table 3 indicates that there is a marked difference in KS2 
Table 3 Performance by key stage, free school meals and ethnic background in Lambeth 2002

\begin{tabular}{|c|c|c|c|c|c|c|}
\hline & \multicolumn{3}{|c|}{ KS2 (\% level $4+$ ) } & \multicolumn{3}{|c|}{$\operatorname{GCSE}\left(\% 5+\mathrm{A}^{*-\mathrm{C}}\right)$} \\
\hline & $\begin{array}{c}\% \text { of pupils } \\
\text { eligible }\end{array}$ & $\begin{array}{l}\text { Free } \\
\text { meals }\end{array}$ & $\begin{array}{c}\text { No free } \\
\text { meals }\end{array}$ & $\begin{array}{c}\% \text { of pupils } \\
\text { eligible }\end{array}$ & $\begin{array}{c}\text { Free } \\
\text { meals }\end{array}$ & $\begin{array}{c}\text { No free } \\
\text { meals }\end{array}$ \\
\hline African & $41 \%$ & $72 \%$ & $76 \%$ & $38 \%$ & $31 \%$ & $48 \%$ \\
\hline Caribbean & $47 \%$ & $65 \%$ & $69 \%$ & $39 \%$ & $22 \%$ & $40 \%$ \\
\hline ESW & $33 \%$ & $60 \%$ & $85 \%$ & $35 \%$ & $19 \%$ & $46 \%$ \\
\hline LEA average & $41 \%$ & $64 \%$ & $77 \%$ & $43 \%$ & $28 \%$ & $46 \%$ \\
\hline
\end{tabular}

performance between pupils eligible for free school meals and the most economically advantaged groups in schools. At the end of primary education, the difference between pupils eligible for FSM and those not is significant, with about $64 \%$ of eligible pupils achieving level $4+$, whereas $77 \%$ of pupils who are not eligible achieve at this level. The GCSE data also shows a significant gap, with pupils on free school meals gaining only $28 \%$ $5+\mathrm{A}^{*}-\mathrm{C}$, compared to $46 \%$ attained by those not eligible. Overall, the findings from the LEA data confirm that pupils eligible for school meals did considerably less well than their affluent peers.

There are also some striking differences within the main ethnic groups when the data are further analysed by pupils eligible for free school meals. Table 3 shows that at GCSE, 22\% of Black Caribbean pupils eligible for free school meals achieved $5+A^{*}-\mathrm{C}$, compared with $40 \%$ of pupils who were not eligible. The White ESW difference is even higher-with a gap of $15 \%$ at KS2 and 27\% at GCSE. However, there are narrower gaps for African and Black Caribbean pupils at KS2. This is despite a high number of pupils on free school meals compared to ESW. This finding underlines the importance of treating any measure of school or LEA performance which does not allow for the influence of background factors such as social class and deprivation with scepticism. Social class data are particularly essential for the analysis of performance of ESW and Black Caribbean in addition to other disadvantage factors. As we have argued in the previous section, our analysis is not complete because of a lack of data on social class. Care must be taken in generalising the results of particularly White ESW pupils from this study to a wider context. A number of studies have confirmed that London's White population is not representative of the social class composition of ESW more generally in the UK, tending to be more skewed towards people with a working-class background (Nuttall et al., 1989; Demie, 2001). Because of the social class profile, it is possible that in inner London, low attainment by White working-class pupils is a particular issue, and that markedly different results might be found in a less disadvantaged rural setting. Further research in other populations outside inner London is clearly required' (Strand, 1999, p. 199).

\section{Underachievement of Black Caribbean Pupils at National Level}

The previous section examined the underachievement of Black Caribbean pupils in the context of the case study LEA, taking into consideration KS2 and GCSE evidence, including factors such as gender and social disadvantage. The main finding from the LEA data clearly shows the underachievement of pupils of Caribbean origin, despite some relative progress between 1998 and 2002. Here we will look in more detail at the attainment of Black Caribbean pupils at national level. 
Table 4 Attainment by ethnic group in primary and secondary schools in England, 1998 and 2002

\begin{tabular}{|c|c|c|c|c|c|c|c|c|c|c|c|}
\hline \multirow[t]{3}{*}{ Ethnic group } & \multicolumn{7}{|c|}{ KS2 Results (Percentage Level $4+$ )* } & \multicolumn{4}{|c|}{ GCSE } \\
\hline & \multicolumn{3}{|c|}{$1998 * *$} & \multicolumn{4}{|c|}{$2002 * * *$} & \multirow{2}{*}{$\begin{array}{c}2000 * * \\
5+ \\
A^{*-C}\end{array}$} & \multirow{2}{*}{$\begin{array}{c}1998 * * \\
5+ \\
A^{*}-\mathrm{C}\end{array}$} & \multirow{2}{*}{$\begin{array}{c}2000 * * \\
5+ \\
\mathrm{A}^{*-\mathrm{C}}\end{array}$} & \multirow{2}{*}{$\begin{array}{c}\text { Change } \\
98-2002 \\
* * * *\end{array}$} \\
\hline & English & Maths & Mean & English & Maths & Mean & $\begin{array}{c}\text { Change } \\
98-2000 \\
* * * *\end{array}$ & & & & \\
\hline White & 62.3 & 57.5 & 59.9 & 74.2 & 71.7 & 72.9 & 13 & 44.3 & 47 & 51 & 6.7 \\
\hline Black Caribbean & 56 & 44.3 & 50.2 & 66.1 & 58.8 & 62.5 & 12.3 & 22.2 & 25.3 & 30 & 7.8 \\
\hline Black African & 54.5 & 43.9 & 49.2 & 66.3 & 60.6 & 63.5 & 14.3 & 33.9 & 34.8 & 40 & 6.1 \\
\hline Indian & 66.5 & 60 & 63.3 & 78.5 & 75.9 & 77.2 & 14 & 53.2 & 57.9 & 64 & 10.8 \\
\hline Pakistani & 47.1 & 37.4 & 42.3 & 59.7 & 55.6 & 57.7 & 15.4 & 31.1 & 34.5 & 40 & 8.9 \\
\hline Bangladeshi & 49.5 & 40.1 & 44.8 & 62.9 & 61.5 & 62.2 & 17.4 & 29.7 & 37.1 & 45 & 15.3 \\
\hline Chinese & 73.7 & 75.3 & 74.5 & 85.6 & 87.4 & 86.5 & 12 & 64.7 & 73.5 & 73 & 8.3 \\
\hline National & 64 & 58 & 60.5 & 75 & 72 & 71 & 10.5 & 46.3 & 47.9 & 51 & 4.7 \\
\hline
\end{tabular}

Source:

*Based on those LEAs providing data for the group for 1998 and 2000 to the DfES as part of the Ethnic Minority Achievement Grant (EMAG) Action Plans and Targets. In 2000 about 135 LEAs completed KS2 returns and 118 completed GCSE returns. The number in 1998 is even much lower compared to 2000 as only 81 and 70 LEAs provided KS2 and GCSE information respectively to the DfES.

**DfES (2002) Ethnic minority achievement grant: analysis of LEA action plans research report 371, HMS, September, 11-12. ***DfES (2003) Aiming high: raising the achievement of ethnic minorities pupils, March (PLASC 2002 data).

****Improvement percentage point changes between 1998 and 2000 for KS2 and 1998 to 2002 for GCSE.

As discussed above, comparing attainment and performance trends for each ethnic group is a major problem at national level due to lack of data. However, recently the DfES started collecting the data as part of the EMAG action plans and LEA targets for KS2 and GCSE. There are variations between the LEAs on the quality of data recorded and not all LEAs have provided a response to each question for each plan year (DfES, 2002). Table 4 shows the KS2 and GCSE results for each group at national level for 1998 and 2000. The main findings from this data show that nationally, there are marked differences in performance between different ethnic groups. Broadly speaking, Chinese, Indian and White heritage pupils are the highest achieving groups, followed by Black African, Bangladeshi and Black Caribbean at KS2. Black Pakistani is the lowest achieving group. Overall the rates of improvement between 1998 and 2000 were higher for Whites (13 percentage points), Pakistani (15 percentage points); Bangladeshi (17 percentage points) and Indian (14 percentage points). The average attainment of Black Caribbean pupils has improved less rapidly (12 percentage points) when compared to other groups. As a result there has been a widening of the attainment gap for Black Caribbean heritage pupils at KS2 at national level.

As at KS2, Chinese, Indian and White heritage pupils are the highest achieving groups at GCSE. This is not surprising, as the findings from a number of previous studies came to similar conclusions (Demie, 2001; Gillborn \& Mirza, 2000; Gillborn \& Gipps, 1996). Perhaps the most important new evidence from the national data is that there is now some evidence that Chinese, Bangladeshi and Indian heritage pupils are improving at higher rates, narrowing the gap with White. However, there have not been sufficient rates of improvement for Black African and Black Caribbean to narrow the gap (see table 4 and Figure 5). As with findings from previous studies the data highlight a particular disadvantage experienced by Black Caribbean pupils in English education systems (Demie, 2001; Gillborn \& Mirza, 2000; Gillborn \& Gipps, 1996). To date it has been difficult to draw generalisable 
$5+A^{*}-C$ GCSE Performance by Ethnic Background, 2002

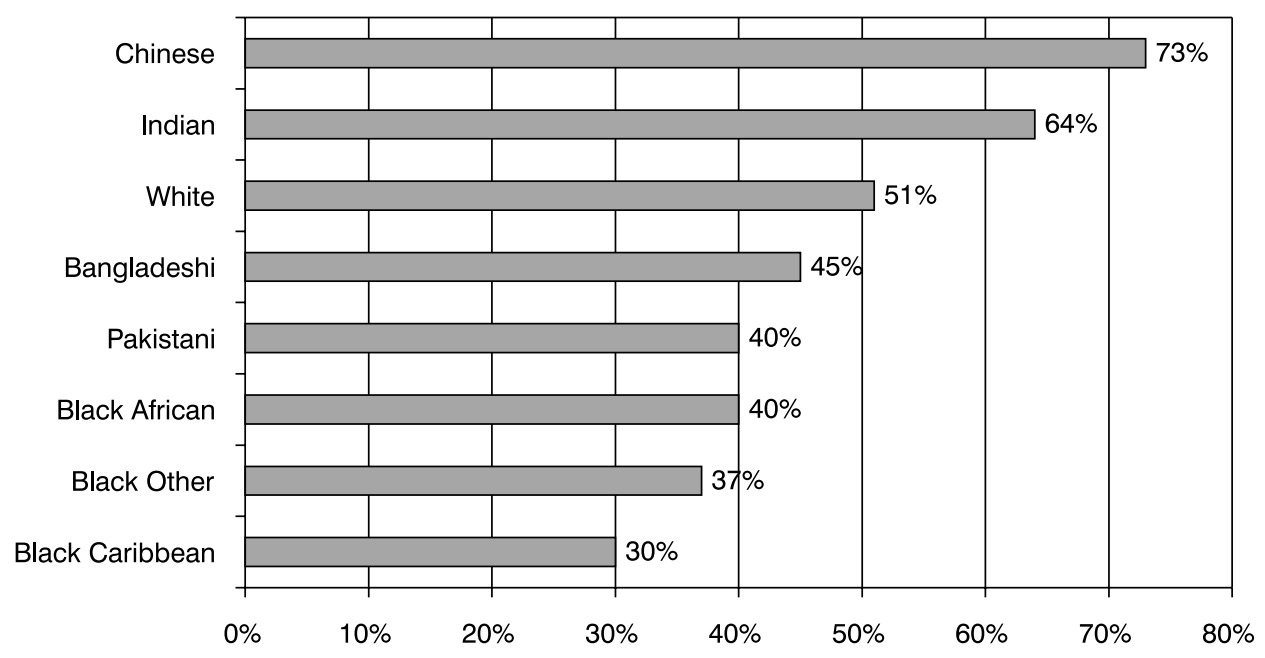

Figure 5. GCSE performance by ethnic groups in England $\left(5+A^{*}-C\right)$

Source: DfES (2003) Aiming High: raising the achievement of ethnic minorities pupils, March (PLASC 2002 data).

conclusions from research on Black Caribbean educational achievement because the YCS data at a national level categorized a range of ethnic groups as Black or African-Caribbean, making it difficult accurately to establish the relative achievement of Black Caribbean pupils compared to English/Scottish/Welsh and other ethnic groups. But the new national data are at least helpful and confirm that Black Caribbean and African pupils have not shared equally in increasing rates of achievement and it has actually worsened (see figure 5). These findings have important implications for strategies of raising achievement. The ethnic groupings and findings at least makes it easier for researchers to examine the differences in experience between pupils from different ethnic groups and for practitioners to identify appropriate strategies to tackle perceived problems

Overall the LEA and national data support that previous finding that 'the gap is growing between the highest and lowest achieving ethnic groups' (Gillborn \& Gipps, 1996, p. 78) and Black Caribbean heritage pupils are achieving on average significantly below the level of other main ethnic groups at GCSE and KS2. However, it is important we interpret this finding with caution. As pointed out above, the achievement of each ethnic group is incomplete for a number of LEAs at national level (DfES, 2002) and the White category is too aggregated and distorted by including groups such as Portuguese, Turkish and Greek who are underachieving (mainly because of problems with English acquisition) at national level. It is difficult to establish accurately the relative achievement of English/Scottish/Welsh heritage pupils and compare with Black Caribbean performance at national level. Evidence from other studies suggests the achievement of English/Scottish/Welsh is higher than reported for White above and it may be even possible the gap in performance with Black Caribbean even wider than suggested by this study (Demie, 2001; Gillborn \& Gipps, 1996).

The reasons for underachievement of Black Caribbean pupils at the LEA and national level are wide-ranging and complex. A number of factors were considered for the underachievement of Caribbean and Black pupils including inappropriate curriculum and teaching materials, prejudice on the part of some teachers, discrimination in the labour market and 
the discouraging effect of relatively poor employment prospects after leaving school, lack of adequate support to schools and teachers from Caribbean and Black parents, inadequacy of the understanding of Caribbean and other Black children by schools and teachers, differences in socio-economic conditions including economic deprivation, poor housing and home circumstances (Rampton, 1981; Swann, 1985) and lack of understanding and missed opportunities for effective partnership between parents and schools. Figueroa (1991, p. 151) gave the main reason for underachievement is that 'the Caribbean pupils were in an unequal position in the British education system and that this system is failing them'. Recent work supports this assertion and pointed out institutional racism and the failure of the National Curriculum to reflect adequately the needs of a diverse and multi-ethnic society (MacPherson, 1999; Gillborn, 2002) as one of the major reasons for the underachievement of Caribbean pupils.

Many of these issues and factors affecting the performance of Caribbean pupils have been documented at length and continually discussed by Black community members, parents and teachers. However, within education literature recently four main schools related factors have emerged. Stereotyping, teachers' low expectations, exclusion and headteachers' poor leadership on equality issues can perpetuate low attainment and disengagement from learning by ethnic minority pupils. Past research into teachers' low expectations has noted that Caribbean students are more likely to be seen as having low academic ability by some teachers (Gillborn, 1990, 1995). Black Caribbean pupils have often been compared unfavourably with Indian and Chinese pupils in research reports, and are seen to exhibit more challenging behavior by classroom teachers (Gillborn, 1990). Black males in particular are seen as more confrontational and less likely to obey school rules (Sewell, 1997). The placing of Black pupils within low ability groups for behavioral reasons and the stereotypical assumptions which often inform these decisions in a number of schools, can only have a negative impact on the ability of them to achieve well.

School exclusions have also been noted to have a direct effect on the ability of Caribbean pupils to achieve academically. For example, in 1996/97, the government's Social Exclusion Unit (1998) estimated that there were over 100,000 temporary exclusions and around 13,000 permanent exclusions in English schools. In these national school exclusion statistics, Black pupils (i.e., Black African, Black Caribbean and Black Other) are over-represented and they are the most frequently excluded pupils. The figure for Black Caribbean is the worst and they are more than six times more likely than White pupils to be excluded (Gillborn \& Gipps, 1996; Blackstone, 1998; Social Exclusion Unit, 1998). As a result of this pattern, Black Caribbean children tend to be stereotyped as being potentially disruptive. One of the most worrying aspects of research related to exclusions from schools in England is that Black Caribbean pupils seem to attract comparatively harsh punishment for things for which White children might not be punished. Evidence suggests that some teachers take any querying of their decisions by Black children or parents as an accusation of racism, and others are swift to label the individual Black child as insubordinate and a group of Black pupils as threatening. There are also some teachers and policy makers at national level who still see Black children as having particularly intractable behavioural problems by virtue of their culture, family structure or upbringing. This disproportionate number of Black Caribbean children exclusions in England and explanations of high exclusions as another element in the social pathology of the Black family, rather than institutional racism that works against the poorest section of the Black community, is obviously of considerable concern. Overall, large numbers of pupils miss vital parts of their education because of exclusions from schools and this has prevented them from achieving their full potential in examinations (Gillborn \& Gipps, 1996; Blackstone, 1998; Social Exclusion Unit, 1998). 
Another factor that contributed to Black Caribbean underachievement is linked to lack of knowledge and awareness of teachers and decision makers about the culturally diverse nature of the ethnic minorities communities served by the school system in England and particularly the Black Caribbean. Still a number of teaching staff, governors and policy makers are not aware of and do not understand Black Caribbean pupils' history and cultural background of the Caribbean community and its difference from the White community. A number of studies suggest that many teachers in British schools hold stereotypical views about ethnic minority pupils which, in general, lead to conclusions that Asian pupils are better behaved and more highly motivated than their African and Caribbean counterparts. Teachers' expectations of Asian pupils will be more positive compared to Black pupils and there is a general belief that Black Caribbean pupils particularly are constrained by community cultural practices and low parental expectations of their children's academic achievement (Blackstone, 1998).

\section{Challenges for Policy Makers and Schools}

The challenge from this research for national policy makers is that the government needs to recognise that the underachievement of Caribbean pupils is an important part of raising standards in schools. Unfortunately it is an unacknowledged problem at national level and there are no specific initiatives to address the situation. The biggest obstacle to raising Caribbean achievement is the 'colour blind' approach which has put the group at a disadvantage and the failure of the National Curriculum to adequately reflect the needs of a diverse, multi-ethnic society (Gillborn, 2002; Macpherson, 1999). All government education reform acts and White papers failed to explore the specific needs of Black Caribbean pupils (Gillborn, 1995). The government has taken up standard rhetoric for all and failed to act decisively against the significant and growing inequalities gap that now characterises the system. Although the government has added into its policy statements on social justice, inclusion and in equality of education attainment between social groups, there has been no strong lead given to address issues of the underachievement of Caribbean pupils by central government (DfEE, 1997). It has failed to recognise that children of Caribbean origin have particular needs that are not being met by the school system.

The reasons for the lack of intervention may be that it was felt that some of the government's existing policies and initiatives such as the National Literacy and Numeracy strategies, Excellence in Cities and EMAG strategies in which targeted resources were put into LEAs and some geographical areas would address the issues of the underachievement of certain groups. However, our findings suggest that these national priorities and strategies do not address the needs of Caribbean pupils. Theses services lacked local innovations and were too highly centralised to meet central government policy. There is no overall, binding theme throughout the programme that recognises Caribbean achievement as an issue and presents coherent and consistent strategies to address it, particularly in relation to teaching and learning styles. Evidence from the case study LEA suggests that the gap in performance is widening as a result of a number of government initiates and Black Caribbean children in England's schools are not sharing the higher educational standards achieved over the last decade. Such evidence reinforces the findings of previous research, which identified serious concerns about the extent to which the education system and schools were meeting the needs of Black Caribbean children (Gillborn \& Mirza, 2000; Rampton, 1981; Swann, 1985; Gillborn \& Gipps, 1996). The concerns persist and there is now a challenge for central government to change its policy towards raising the achievement of Caribbean pupils with targeted initiatives and ring- 
fenced funding policies to support local initiatives in some geographical areas or LEAs. LEAs have a central role to play in supporting schools to raise standards and are crucial in assisting schools to establish a well-focused programme, but lack resources to undertake innovative local initiatives such as raising the achievement of Caribbean pupils. The government could take a stronger lead and demonstrate that race equality is a real priority by providing additional funding to assist LEAs and schools to support targeted local initiatives. We urge the government to make a fresh start. We believe that, if it could focus its energy on the underachievement of Black Caribbean pupils and set a new tone by working with local authorities, it would have a better chance of raising standards. These are local issues that are better addressed by innovative LEA initiatives, such as the Raising Achievement of Caribbean pupils project, with involvement of local communities and schools in the formulation of the project.

There are also other challenges for LEAs and schools. Although there is now greater recognition of the underachievement of Black Caribbean pupils in schools and LEAs, there is less intervention work on the ground to support this group compared to early 1990s. It is rare to find in LEAs these days a project relevant to the needs of pupils of Caribbean heritage. OFSTED have commented on the worrying picture, as this group lack effective support. Most of the additional EMAG funds provided by central government are directed at school level for posts that focus on additional support to bilingual pupils or to improve home school liaison. OFSTED has also noted that a small number of posts were planned in LEAs and schools but only a few appointments have been made because of lack of funds (OFSTED, 1999, 2001). Research evidence from Lambeth and Tower Hamlets in the early 1990s suggests these local initiatives are essential for raising standards (Gillborn \& Gipps, 1996). The Raising Achievements Projects (RAP) in these two LEAs that targeted a number of underperforming schools have helped in the improvement of the average exam scores of pupils in each school involved and have helped Caribbean and Bangladeshi pupils to achieve higher average exams scores. However, since 1988 the government has become overideological on the question of what can be done by local and central government. It restricted local innovations, lacked will and data to formulate policy and strategies. Schools have also lacked clarity and direction when it came to addressing inequalities of attainment between different ethnic groups and local authorities have lacked the resources to innovate and implement targeted programmes to meet the needs of the local communities it serves. Therefore, to tackle underachievement schools and LEAs need to develop targeted initiatives that go beyond the current highly centralised national and numeracy strategies and Ethnic Minority Achievement (EMAG) initiatives to identify and address the needs of pupils of Black Caribbean heritage.

\section{Conclusion}

In this study we examined educational inequalities and the underachievement of Caribbean pupils in schools. A number of conclusions can be drawn from key stages and GCSE evidence. The findings of the case study LEA and national data suggest that:

- Children from different ethnic groups show differences in educational attainment at the end of each key stage. Indian, Vietnamese and Chinese children achieve higher results, on average than African, Caribbean, Irish and English/Scottish/Welsh pupils.

- The performance of pupils of Black African origin is higher than that of Black Caribbean pupils at all key stages. This is hardly surprising, given that the majority of the African pupils both at LEA and national level are of Nigerian or Ghanaian origin or other African countries which have well developed school systems (see Demie et al., 2003). 
- Caribbean pupils tend to make a start to their primary schooling, which is broadly in line with national average, but then underachieve at the highest levels of attainment and underachieve markedly in secondary schools. The gap in performance is particularly widening at GCSE compared to ESW and African pupils.

- Overall the achievement of Caribbean pupils is a particular cause for concern. People of Caribbean origin make up the largest ethnic minority group particularly in the LEA. The underperformance of this group is a major problem and it is important that secondary schools in particular establish what is happening to Black Caribbean pupils to cause a good start in primary schools to turn into such a marked decline. There is a need for strategies to be developed to raise levels of achievement of this group and to reverse the trends in this LEA and at national level.

- A number of factors were considered for the underachievement of Caribbean and Black pupils, including teachers' low expectations, stereotyping, exclusion, headteachers' poor leadership on equality issues, lack of awareness of Caribbean and other Black children's culture and history by schools and teachers, institutional racism, inappropriate curriculum and the failure of the National Curriculum to reflect adequately the needs of a diverse and multi-ethnic society.

\section{Policy Implications}

We feel the improvement of awareness of teaching staff, governors and policy makers about Black Caribbean culture and its difference from that of the White population as one of the keys to success in the whole question of raising achievement. Unfortunately, this is not the case at national level and a number of studies suggest that many teachers hold stereotypical views about ethnic minority pupils and there is a lack of awareness about Black Caribbean cultural and underachievement issues. There is a lot of work to be done with teachers and management in understanding the roots of Caribbean culture and Black Caribbean pupils as learners, how and why some underachieve and what teachers can do about it. There is a number of ways in which this can be done at national level. Schools are now data rich environments and our study confirms that they moved from a decade ago where the majority of pupils sat no formal tests or examination until they were 15 to one where children are formally assessed at ages 7 , 11, 14 and 15. These pupil-level data, along with national and LEA comparative data, provide teachers with the necessary tools to identify pupil underachievement, set targets, monitor progress and evaluate performance. A further examination of these key stage and GCSE results by ethnicity will, in most schools, also throw up discrepancies of achievement. We therefore recommend the extensive use of data analysed by ethnicity to check the participation and achievement of ethnic groups in schools. This was powerful in the case study LEA. Teachers also need to think carefully about the contribution they can make in raising the awareness of those around them including pupils, parents and colleagues and challenge them to participate in the wider campaign to raise achievement. However, the evidence that this happens is mixed. Teachers may need a course and seminar about the issue of raising Black Caribbean achievement and practical resources for use in schools to challenge racism and negative stereotyping. Schools and LEAs should provide some high quality in-service training for all staff as a way into the issue so that the needs of ethnic minority pupils can be tackled with confidence.

In addition, it is important that the governing body is also made aware of the issue. This again can be done through the annual discussion of the results of the key stage tests and/or GCSEs. In some cases, governors may wish to form specific working party 
or have the issue regularly discussed on the agenda. It is also useful to have a variety of awareness-raising activities over a period of time so that a rolling programme can be developed, keeping the issue at the forefront of thinking. Headteachers and governors should gather and debate the views of staff, pupils, parents and their wider community about barriers to achievement.

\section{Implications for Future Research}

There are some clear areas where research is needed if we are to have a fuller picture about factors that influence Caribbean pupils' academic achievement. The body of available research suggests that there is a lack of research into factors that contribute to educational success and high academic achievement among ethnic minority groups in the UK. There has also been little research into how the experience of successful schools may be disseminated within the LEA to address underachievement in other similar schools.

The first step in answering these questions is to identify the factors that contribute to success. Recent research by the LEA (McKenley et al., 2003) and OFSTED (2002) has identified characteristics of successful schools and has discussed these features in detail, including strong and purposeful leadership, high expectation for all pupils and teachers, effective use of data, effective teaching and learning, an inclusive curriculum that meet the needs of Black Caribbean children and inner London pupils, a strong link with the community, a clear commitment to parents' involvement, good and well-coordinated support to Black Caribbean pupils through extensive use of learning mentors and role models and effective use of Black and White teachers as advocates and role models. The findings of this case study LEA (see McKenley et al., 2003) confirm that in good schools Black Caribbean pupils do well, and they offer some useful pointers for developing effective approaches to tackling underachievement in general. However, this study is from one LEA and there is a need to extend this study to national level. To improve our knowledge of good practice there is a need to undertake further research in selected 'successful' schools in other LEAs to identify a number of significant common themes for success in raising the achievement of Caribbean heritage pupils. These should include a detailed examination of leadership and management, curriculum provision, developing a culture of high expectations and a commitment to community representation.

Correspondence: Feyisa Demie, Research and Statistics Unit, Lambeth Education, International House, Canterbury Crescent, London, SW9 7QE, UK. Email: fdemie@lambeth.gov.uk

\section{Acknowledgements}

The author would like to acknowledge helpful comments on the draft copy from Michael Peters, Director of Lambeth Education.

\section{Notes}

[1] This article is based on a paper presented to the Annual Conference of British Educational Research Association (BERA), Exeter University, Exeter, 12-14 September 2002. The views expressed in this paper are those of the author and are not to be taken as the views of Lambeth Education. 


\section{References}

AsHARIF, S. (2002) QCA and the politics of multicultural education, Multicultural Teaching, 20, $3,24-27$.

BBC News (1998, 9 December) Schools told to do more for Black pupils.

BBC News (2002, 12 March) Fast tracking will penalise Black pupils.

BBC News (2002, 16 March) Task force to help Black pupils.

Blackstone, T. (1998) Towards learning society: can ethnic minorities participate fully? In: T. Blackstone, B. Parekh \& P. Sanders (eds) Race Relations in Britain: a developing agenda, London, Routledge.

Blair, M. \& Bourne, J. with Coffin, C., Creese, A. \& Kenner, C. (1998) Making the Difference: teaching and learning strategies in successful multi-ethnic schools, London, Department for Education \& Employment.

Blunkett, D. (2000) Raising aspirations for the 21 st century. Speech to the North of England Education Conference, Wigan, 6 January.

Demack, S., Drew, D. \& Grimsley, M. (2000) Minding the gap: ethnic, gender and social class differences in attainment at 16, 1988-95, Race Ethnicity and Education, 3, 2, 117-143.

Demie, F. (2001) Ethnic and gender difference in educational achievement and implications for school improvement strategies, Educational Research, 43, 1, 91-106.

Demie, F., Taplin, A. \& Butler, R. (2003) Stages of English acquisition and attainment of bilingual pupils: implications for pupil performance in schools, Race Equality Teaching, 21, 2, $42-48$.

Department of the Environment, Transport and Regions (DETR) (2001) Raising Attainment in Education, Beacon Council Year 2 Theme Research. Available at: www.local.dtlr.gov.uk/research

DfEE (1997) Excellence in Schools, Cm 3681, London, HMSO.

DfEE (2001) Youth Cohort Study: the activities and experiences of 16 year olds, England and Wales 2000, London, The Stationery Office.

DfEE (2001) DfES Statistics for Education-Public Examinations GCSE and GCE in England, London, DfEE.

DFES (2003) Aiming High: raising the achievement of ethnic minority pupils, a consultation paper, London, Department for Education and Skills.

DfEE (1999) DfES Statistics for Education - Schools in England, London, DfEE.

FigueroA P. (1991) Education and the Social Construction of Race, London, Routledge.

Gillborn, D. (1990) 'Race', Ethnicity and Education: teaching and learning in multi-ethnic schools, London, Unwin Hyman.

Gillborn, D. (1995) Racism and Antiracism in Real Schools: theory, policy and practice, Buckingham, Open University Press.

Gillborn, D. (2002) Education and institutional racism. Inaugural professorial lecture, Institute of Education, University of London.

Gillborn, D. \& GipPs, C. (1996) Recent Research on the Achievement of Ethnic Minority Pupils, OFSTED Reviews of Research, London, HMSO.

Gillborn, D. \& Mirza, H.S. (2000) Educational Inequality: mapping race, class and gender, London, OFSTED.

Gillborn, D. \& Youdell, D. (2000) Rationing Education: policy, practice, reform and equity, Buckingham, Open University Press.

Gillian, K. \& Richardson, R. (2003) News and comments, Race Equality Teaching, 21, 2, $4-5$.

Guardian (2002, 7 May) Schools called to account for ethnic divide.

ILEA (1987) Actual and Predicted Examination Scores in Schools, London, ILEA Research and Statistics Branch. 
Kamin, L.J. (1977) The Science and Politics of IQ, Harmondsworth, Penguin.

Kendall, L. (1998) Report on the Analysis of 1997 Examination Results: NFER/AMA project on examination results in context, London, Association of Metropolitan Authorities.

Mabey, C. (1981) Black British literacy, Educational Research, 23, 2, 83-95.

MacPherson, W. (1999) The Stephen Lawrence Inquiry, CM 4262-I, London, The Stationery Office.

McKenley J., Power, C., Ishani, L. \& Demie, F. (2003) Raising Achievement of Black Caribbean Pupils: good practice in Lambeth schools, London, Research and Statistics Unit, Lambeth Education.

Mortimore, P., Sammons, P., Stoll, L., Lewis, D. \& Ecob, R. (1988) School matters: the junior years, Somerset, Open Books.

Nuttall, D., Goldstein, H., Prosser, R. \& Rasbash, J. (1989) Differential school effectiveness, International Journal of Educational Research, 13, 769-776.

NutTald, D. (1990) Difference in Examination Performance, RS 1277/90, Research and Statistics, ILEA, London.

Observer (2002, 6 January) Teachers are failing Black boys.

OFSTED (1999) Raising the attainment of minority ethnic pupils: school and LEA responses. Available at: www.ofsted.gov.uk/publications/.

OFSTED (2001) Managing Support for the Attainment of Pupils from Minority Ethnic Groups. Available at: www.ofsted.gov.uk/publications/.

OFSTED (2002) Achievement of Black Caribbean Pupils: three successful primary schools. Available at: www.ofsted.gov.uk/publications/.

OFSTED (2002) Achievement of Black Caribbean Pupils: good practice in secondary schools. Available at: www.ofsted.gov.uk/publications/.

Rampton, A. (1981) West Indian Children in Our Schools, Cmnd 8273, London, HMSO.

SEwell, T. (1997) Black Masculinities and Schooling: how black boys survive modern schooling, Stoke-onTrent, Trentham.

Smith, D.J. \& Tomlinson, S. (1989) The School Effect: a study of multi-racial comprehensives, London, Policy Studies Institute.

Social Exclusion Unit (1998) Truancy and Exclusions, London, HMSO.

Social Exclusion Unit (1999) Bridging the Gap: new opportunities for 16-18 year olds not in education, employment or training, London, The Stationery Office.

STRAND, S. (1999) Ethnic group, sex and economic disadvantage: associations with pupils' educational progress from baseline to the end of KS1, British Educational Research Journal, 25, 179-202.

Swann, LoRd (1985) Education for All: final report of the Committee of Inquiry into the Education of Children from Ethnic Minority Groups, Cmnd 9453, London, HMSO.

TAYLOR, M.J. (1981) Caught Between: a review of research into the education of West Indian Origin, Windsor, National Foundation for Educational Research (NFER).

Thomas S., Nuttall, D. \& Goldestein, H. (1994) Report on Analysis of 1992 Examination Results, London, Association of Metropolitan Authorities (AMA).

Tomlinson, S. (1983) Ethnic Minorities in British Schools: a review of literature 1960-82, Policy Studies Institute, London. 